\title{
Natural monoacetylenes studied by quantum-chemical chemistry
}

\author{
Maciej Roman and Malgorzata Baranska* \\ Faculty of Chemistry, Jagiellonian University, Krakow, Poland
}

\begin{abstract}
This study is a part of the project focused on the vibrational analysis of natural mono- and polyacetylenes by using Raman spectroscopy and theoretical calculations. Their vibrational spectra show strong and polarized $-\mathrm{C} \equiv \mathrm{C}-$ bands in the region of about $2200 \mathrm{~cm}^{-1}$. Mono- as well as polyacetylenes are supposed to be active in plants yet not available in an isolated form, so theoretical simulation of their vibrational spectra and comparison with the registered ones seems to be an excellent way to confirm or exclude the presence of these compounds in the investigated plants. Such an approach was applied here to analyze polyacetylenes in roots of Coreopsis grandiflora. According to literature, this plant should contain a monoacetylene substituted by a thiophene ring. Theoretical calculations allowed to confirm this assumption.
\end{abstract}

Keywords: Mono- and polyacetylenes, DFT, Raman spectroscopy

\section{Introduction}

Mono- and polyacetylenes are common compounds in a large number of natural products. In most cases these secondary metabolites are unique to individual plant species, usually occur in low concentrations (in the order of $0.01-1 \%$ ) and are not essential to plant cell survival. It is assumed that their function or importance is mainly related to ecological aspects as they are used for defense against predators, parasites and diseases. They have proven to be important biologically active components that can be used as antibacterial, antimicrobial, antifungal and antiviral agents [5]. Moreover, they also exhibit larvicidal activity and cytotoxicity towards a range of cell lines. However, the investigation of these compounds is difficult because of their unstability and sensitivity to heat and light, thus the isolation of some polyacetylens can be a significant problem. In the case of impurities or no availabilities of standards of mono- and polyacetylenes to compare with the spectra taken from the plant, their identification can be impossible. In order to overcome these problems theoretical calculations were applied in this work.

Monoacetylenes posses a conjugated triple bond system. The presence of substituents influence the frequency and intensity of the $-\mathrm{C} \equiv \mathrm{C}-$ stretching modes. Thus, the spectral position of the $-\mathrm{C} \equiv \mathrm{C}-$ vibrations and pattern of Raman bands usually provide enough information to recognize the type of substitution and to support the identification of monoacetylenes [1]. In this work for three model monoacetylenes substituted by a thiophene ring theoretical Raman spectra were calculated in order to compare with the experimental data.

\footnotetext{
${ }^{*}$ Corresponding author: Malgorzata Baranska, Faculty of Chemistry, Jagiellonian University, 3 Ingardena Street, 30-060 Krakow, Poland. Tel.: +48 12 6632253; Fax: +48 12 6340515; E-mail: baranska@chemia.uj.edu.pl.
} 


\section{Computational methods}

All calculations were carried out using the Gaussian'03 package of programs [4]. Geometries and vibrational frequencies of model compounds were calculated by means of DFT method with B3LYP functional [2,6] and the aug-cc-pVDZ basis set [3]. All frequencies were scaled by 0.96 scaling factor.

\section{Results and discussion}

Monoacetylenes occurring in roots of Coreopsis grandiflora are supposed to be biological active, but are not available in an isolated form. Raman spectrum obtained from the roots shows characteristic band at $2194 \mathrm{~cm}^{-1}$ [7]. According to Bohlmann [8], this plant should contain a monoacetylene substituted by a thiophene ring. To verify this assumption theoretical calculations of three model monoacetylenes were performed (Fig. 1). The compounds were optimized and their Raman spectra were simulated.
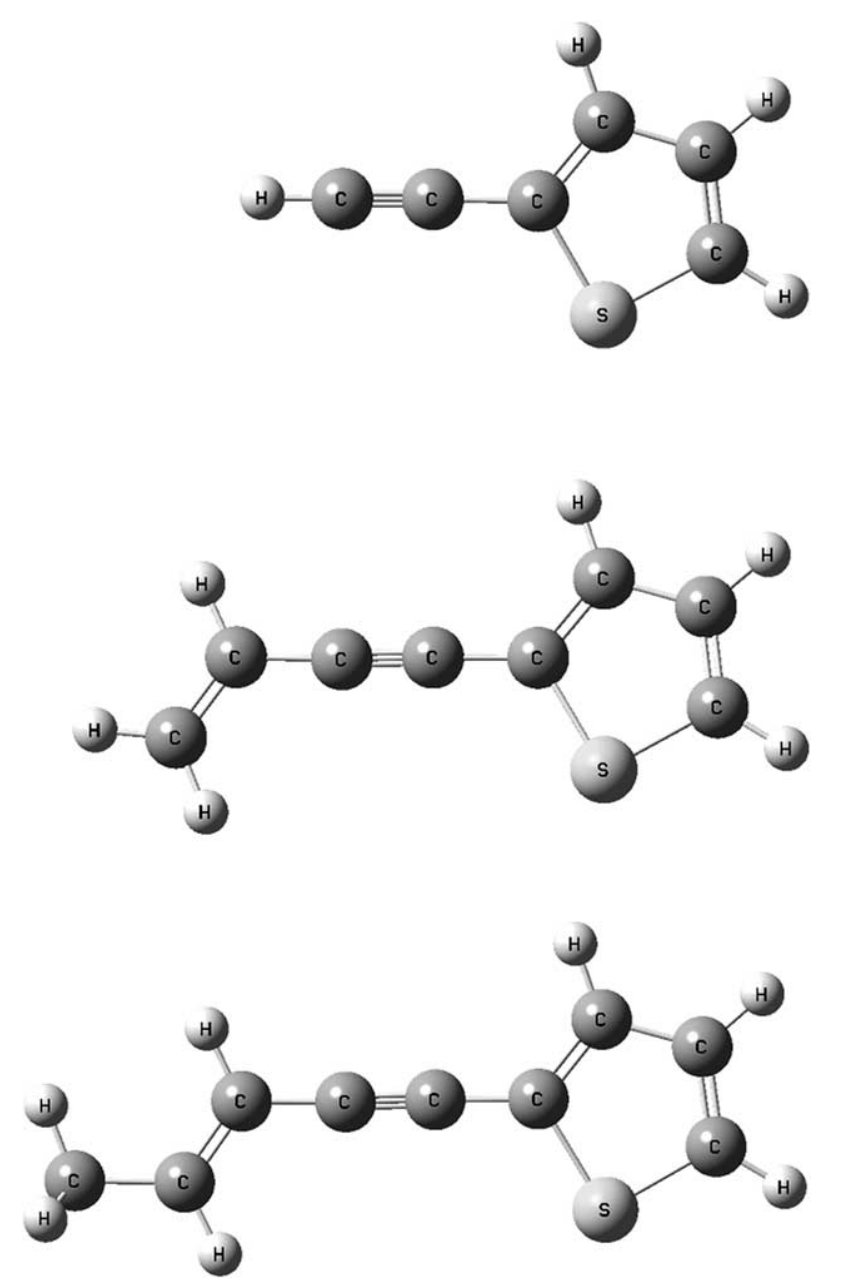

Fig. 1. The geometry of three optimized model monoacetylenes. 
Table 1

The selected bond lengths, angles and dihedrals optimized for three model monoacetylenes

\begin{tabular}{cccc}
\hline MA-Th & V-MA-Th & Al-V-MA-Th & Geometry \\
\hline 1.216 & 1.223 & 1.223 & $-\mathrm{C} \equiv \mathrm{C}-[\AA]$ \\
1.414 & 1.408 & 1.408 & $\equiv \mathrm{C}-\mathrm{C}-(\mathrm{Th})[\AA]$ \\
1.760 & 1.764 & 1.764 & $(\equiv \mathrm{C})-\mathrm{C}-\mathrm{S}-[\AA]$ \\
1.382 & 1.385 & 1.385 & $(\equiv \mathrm{C})-\mathrm{C}=\mathrm{C}-(\mathrm{Th})[\AA]$ \\
- & 1.347 & 1.349 & $-\mathrm{C}=\mathrm{C}-(\mathrm{V})[\AA]$ \\
120.8 & 120.8 & 120.8 & $\angle(\equiv \mathrm{C}-\mathrm{C}-\mathrm{S}-)\left[{ }^{\circ}\right]$ \\
128.7 & 128.9 & 129.0 & $\angle(\equiv \mathrm{C}-\mathrm{C}=\mathrm{C}-)(\mathrm{Th})\left[^{\circ}\right]$ \\
- & 124.9 & 124.8 & $\angle(\equiv \mathrm{C}-\mathrm{C}=\mathrm{C}-)(\mathrm{V})\left[{ }^{\circ}\right]$ \\
- & 0.1 & 1.0 & $\angle(-\mathrm{C}=\mathrm{C} \cdots \mathrm{C}-\mathrm{S}-)\left[{ }^{\circ}\right]$ \\
\hline
\end{tabular}

Table 1 contains selected geometrical parameters of three studied models while the most characteristic frequencies together with their assignment are gathered in Table 2.

The first analyzed monoacetylene is substituted only by a thiophene (MA-Th). For this compound theoretical calculations show very strong band due to $-\mathrm{C} \equiv \mathrm{C}-$ stretching mode at $2111 \mathrm{~cm}^{-1}$. The second monoacetylene considered in this work consists of an acetylene with a thiophene ring and a vinyl group (V-MA-Th). Raman spectrum predicted for this compound gives very strong band due to $-\mathrm{C} \equiv \mathrm{C}-$ stretching mode at $2194 \mathrm{~cm}^{-1}$. The most expanded monoacetylene modeled here is built of a thiophene ring, a vinyl and an alkyl groups (Al-V-MA-Th). Similarly to previous compound theoretical calculations show very strong band due to $-\mathrm{C} \equiv \mathrm{C}-$ stretching mode at $2194 \mathrm{~cm}^{-1}$. All reported here frequencies of $-\mathrm{C} \equiv \mathrm{C}-$ vibration were scaled as reported in computational part.

The obtained results shows that substitution of the monoacetyle with a vinyl group and thiophene ring leads to a good agreement between theoretical and experimental data. Further extension of the substituents does not affect the frequency of $-\mathrm{C} \equiv \mathrm{C}$ - vibrational mode since they are too far from the triple bond. So, the most significant are the closest neighbors of the $-\mathrm{C} \equiv \mathrm{C}-$ system. The presence of additional substituents has no influence on the position of this band. Based on calculations it was possible to exclude from the consideration MA-Th since its Raman signal is moved about $80 \mathrm{~cm}^{-1}$ in comparison to experimental data. Raman band at $2194 \mathrm{~cm}^{-1}$ present in the spectrum of Coreopsis grandiflora roots was predicted also for two investigated model compounds (V-MA-Th and Al-V-MA-Th). So we can conclude that this plant probably contain a monoacetylene substituted by two groups and one of them is a thiophene ring. Generally, theoretical calculations allowed to confirm the assumption found in the literature.

\section{Conclusions}

Due to the lack of monoacetylenes in an isolated form theoretical calculations can be very useful in order to identify these compound in the plant tissues. They give possibilities to predict vibrational spectra, which can be compared directly with the experimental data. Theoretical calculations can be used to built a spectral libraries of essential compounds not available in an isolated form, but which are important for agriculture, ecology or pharmaceutical industry. 
Table 2

The most characteristic frequencies (in $\mathrm{cm}^{-1}$ ) together with their assignment for three model monoacetylenes

\begin{tabular}{cccc}
\hline MA-Th & V-MA-Th & Al-V-MA-Th & Band assignment \\
\hline 673 & 671 & 666 & $\omega(\mathrm{C}-\mathrm{H})$ in ring \\
820 & 813 & 815 & $v(\mathrm{C}-\mathrm{S})$ \\
- & 905 & 930 & $\omega(=\mathrm{C}-\mathrm{H})$ in side-chain \\
1194 & 1161 & 1162 & $v(\mathrm{C}=\mathrm{C})$ and $\rho(\mathrm{C}-\mathrm{H})$ in ring \\
1409 & 1414 & 1414 & $v(\mathrm{C}=\mathrm{C})$ and $v(\mathrm{C}-\mathrm{C})$ in ring \\
1494 & 1495 & 1495 & $v(\mathrm{C}=\mathrm{C})$ in ring \\
- & 1593 & 1621 & $v(\mathrm{C}=\mathrm{C})$ in side-chain \\
2111 & 2194 & 2194 & $v(\mathrm{C} \equiv \mathrm{C})$ \\
3342 & - & - & $v(\equiv \mathrm{C}-\mathrm{H})$ \\
\hline
\end{tabular}

\section{Acknowledgements}

The authors thank for the computing time to the Academic Computer Centre "Cyfronet", Kraków, Poland. This research was supported by the Ministry of Science and Higher Education (MNiSW, Grant No. N204013635, 2008-2011).

\section{References}

[1] M. Baranska and H. Schulz, Spatial tissue distribution of polyacetylenes in carrot root, Analyst 130 (2005), 855-859.

[2] A.D. Becke, Density-functional thermochemistry. III. The role of exact exchange, J. Chem. Phys. 98 (1993), 5648-5652.

[3] T.H. Dunning Jr., Gaussian basis sets for use in correlated molecular calculations. I. The atoms boron through neon and hydrogen, J. Chem. Phys. 90 (1989), 1007-1023.

[4] M.J. Frisch, G.W. Trucks, H.B. Schlegel, G.E. Scuseria, M.A. Robb, J.R. Cheeseman, J.A. Montgomery Jr., T. Vreven, K.N. Kudin, J.C. Burant, J.M. Millam, S.S. Iyengar, J. Tomasi, V. Barone, B. Mennucci, M. Cossi, G. Scalmani, N. Rega, G.A. Petersson, H. Nakatsuji, M. Hada, M. Ehara, K. Toyota, R. Fukuda, J. Hasegawa, M. Ishida, T. Nakajima, Y. Honda, O. Kitao, H. Nakai, M. Klene, X. Li, J.E. Knox, H.P. Hratchian, J.B. Cross, V. Bakken, C. Adamo, J. Jaramillo, R. Gomperts, R.E. Stratmann, O. Yazyev, A.J. Austin, R. Cammi, C. Pomelli, J.W. Ochterski, P.Y. Ayala, K. Morokuma, G.A. Voth, P. Salvador, J.J. Dannenberg, V.G. Zakrzewski, S. Dapprich, A.D. Daniels, M.C. Strain, O. Farkas, D.K. Malick, A.D. Rabuck, K. Raghavachari, J.B. Foresman, J.V. Ortiz, Q. Cui, A.G. Baboul, S. Clifford, J. Cioslowski, B.B. Stefanov, G. Liu, A. Liashenko, P. Piskorz, I. Komaromi, R.L. Martin, D.J. Fox, T. Keith, M.A. Al-Laham, C.Y. Peng, A. Nanayakkara, M. Challacombe, P.M.W. Gill, B. Johnson, W. Chen, M.W. Wong, C. Gonzalez and J.A. Pople, Gaussian 03, Revision E.01, Gaussian, Inc., Wallingford, CT, 2004.

[5] S.L. Hansen, S. Purup and L.P. Christensen, Bioactivity of falcarinol and the influence of processing and storage on its content in carrots (Daucus carota L.), J. Sci. Food Agric. 83 (2003), 1010-1017.

[6] C.T. Lee, W.T. Yang and R.G. Parr, Development of the Colle-Salvetti correlation-energy formula into a functional of the electron density, Phys. Rev. B 37 (1988), 785-789.

[7] B. Schrader, H. Schulz, M. Baranska, G.N. Andreev, C. Lehner and J. Sawatzki, Non-destructive Raman analyses - polyacetylenes in plants, Spectrochim. Acta A 61 (2005), 1395-1401.

[8] E. Winterfeld, Ferdinand Bohlmann (1921-1991) und sein wissenschafliches Werk, Liebigs Ann. Chem. (1994), I-XXXIV. 


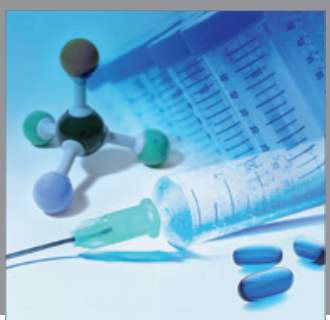

International Journal of

Medicinal Chemistry

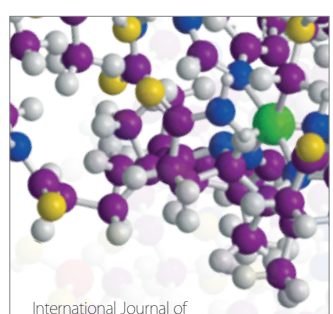

Carbohydrate Chemistry

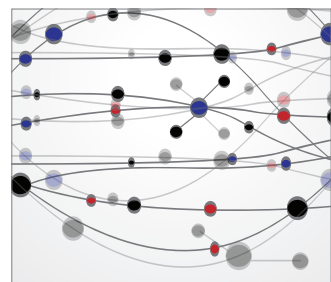

The Scientific World Journal
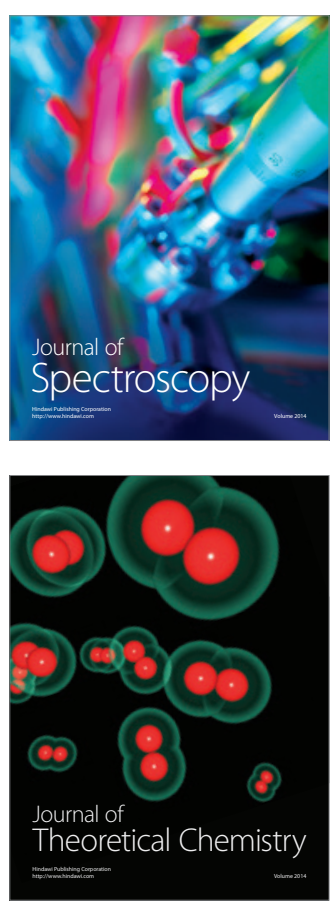
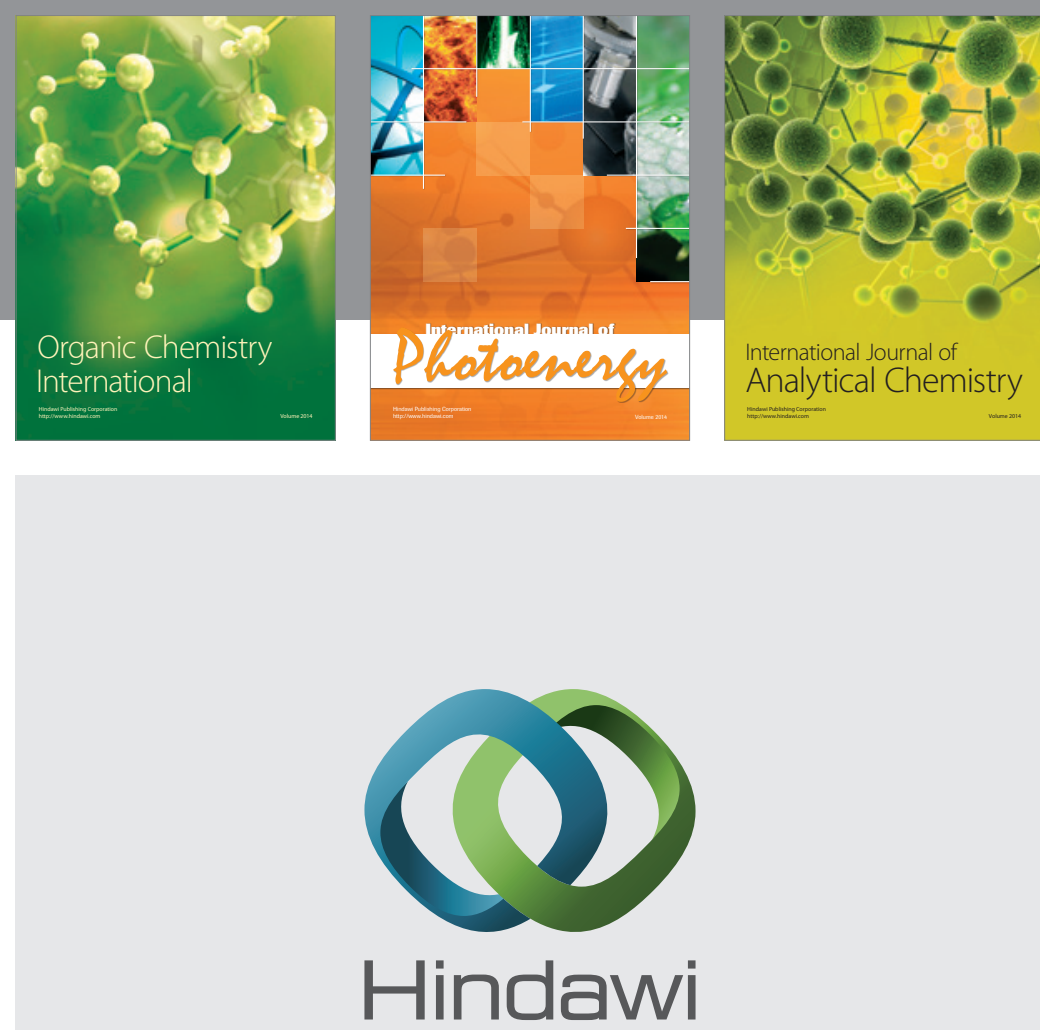

Submit your manuscripts at

http://www.hindawi.com
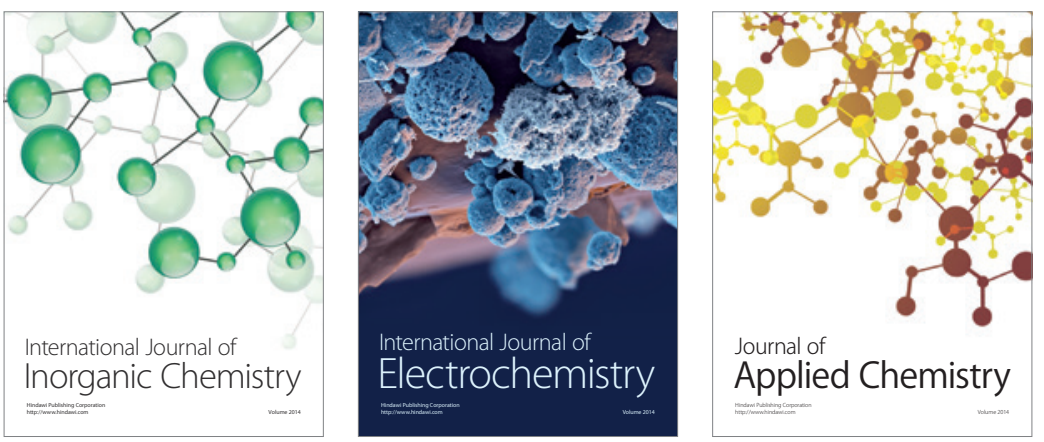

Journal of

Applied Chemistry
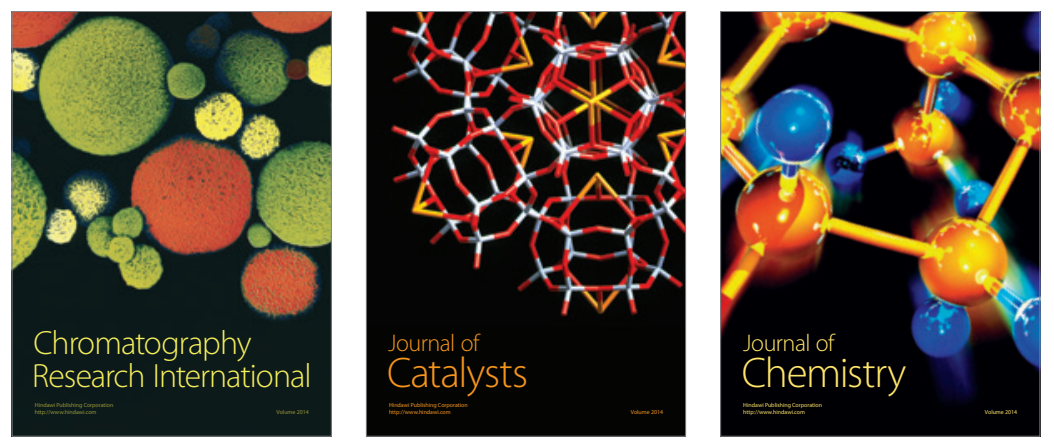
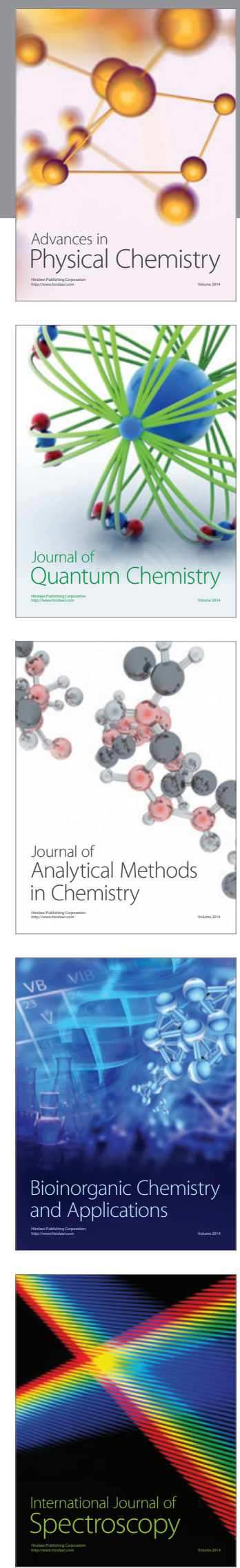